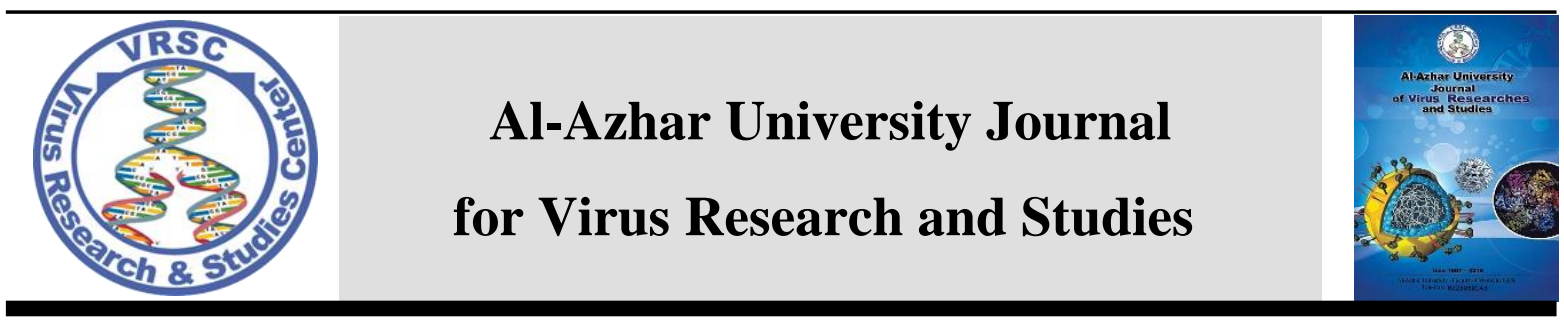

\title{
Association of Adiponectin-11377 C/G (rs266729) Gene Polymorphism with Nonalcoholic Fatty Liver Disease and Metabolic Features in Egyptian Women
}

\author{
Moushira Zaki*1, Marwa Khairy Abdelwahab², Neamat Abdelmageed ${ }^{3}$, Naglaa \\ Hassan $^{1}$ and Rabab Khairat ${ }^{4}$
}

\author{
${ }^{1}$ Biological Anthropology Department, National Research Centre, Egypt \\ ${ }^{2}$ Clinical Pathology Department Faculty of Medicine for girls, Al-Azhar University, \\ ${ }^{3}$ Hepatogastroentrology \& Infectious Diseases Department, Faculty of Medicine for \\ girls, Al-Azhar University, \\ ${ }^{4}$ Department of Medical Molecular Genetics, Division of Human Genetics and Genome \\ Research, National Research Centre, Egypt \\ *E-mail: moushiraz@yahoo.com
}

\begin{abstract}
The present cross-sectional study included 150 unrelated non-alcoholic fatty liver disease (NAFLD) patients and 150 healthy subjects. ADIPOQ (-11377C / G) variant was genotyped with polymerase chain reaction-restriction fragment polymorphism (PCR-RFLP) method for both patients and controls. Anthropometric and biochemistry parameters were measured. The Homeostasis Model Insulin Resistance Assessment (HOMA-IR) was used to assess the insulin resistance. The rs 266729 polymorphism was associated with NAFLD with significant increase in $\mathrm{CG}$ genotype compared to those with the wild genotype $\mathrm{CC}(\mathrm{OR}=9.24,95 \% \mathrm{CI}=4.96$ 17.21, $\mathrm{p}<0.001)$ in co dominant tested inheritance model as well in dominant tested inheritance model with $\mathrm{CG} / \mathrm{GG}$ genotype $(\mathrm{OR}=9.58,95 \% \mathrm{CI}=5.32-17.28, \mathrm{p}<0.001)$. The $\mathrm{G}$ allele increased the risk of NAFLD $(\mathrm{OR}=6.06,95 \% \mathrm{CI}=3.65-10.05, \mathrm{p}<0.001)$ in comparison with $C$ allele. Subgroup comparison in NAFLD revealed significant higher levels of waist circumference (WHR), HOMA-IR, systolic blood pressure (SBP), fasting glucose and LDL-C in GG and GC carriers compared to CC genotype and significant lower levels of serum adiponectin. The study suggests that ADIPOQ gene polymorphism can be used as a helpful biomarker for NAFLD and abnormal metabolic parameters. Our study sheds light on its role that might be played in the pathogenesis of NAFLD. Proper evaluation of NAFLD is likely to improve therapy effectiveness and safety management.
\end{abstract}

Keywords: Non-alcoholic fatty liver disease; Adiponectin; Genetic markers.

\section{Introduction}

Non-alcoholic fatty liver disease is emerging as a prevalent chronic disorder, especially in developed countries where it become the most common form of chronic liver diseases in recent years [1]. According to mepidemiological figures, the global prevalence of NAFD is almost $25 \%$, with the highest prevalence in Middle Easy (32\%) and South America (30\%) [2], [3]. From pathological point-of-view, NAFLD 
can be represented by wide variations in the pathological changes ranging from hepatic steatosis to non-alcoholic steatohepatitis and may progress to liver fibrosis [4]. NAFLD is an important cause of mortality and morbidity in both developing and developed countries, patients with NAFLD are at increased risks of advanced liver diseases, hepatic failure, hepatocellular carcinoma, and hepatic-related death [5]. Moreover, previous reports lined NAFLD with higher risks of cardiovascular disease, low-grade inflammation, and macro and micro-vascular complications [6], [7].

While the exact pathogenesis of NAFLD is not fully understood, it is believed that the development of NAFLD is multifactorial in origin with interaction of genetic, hormonal, and nutritional factors. A cumulative body of evidence has shown that the frequencies of various genetic polymorphisms, such as PNPLA3, LIPA, and HMOX-1 genes are higher in NAFLD patients than general population [4], [8]. While hyperinsulinemia, obesity and type 2 diabetes are important contributors to higher level of lipolysis and hepatic deposition of free fatty acids (FFA) which are the hallmark of NAFLD pathophysiology [9]. Insulin-resistance is another risk factor which induces increased plasma FFA concentration. Moreover, it was demonstrated that insulin-resistance impairs the circulating levels of adipokines (such as adiponectin) and increases the level of cytokines which in return induce further increase in fat deposition within hepatocytes [10], [11].

On the other hand, with the recognition of adipose tissue as an endocrine organ, adipokines have emerged as crucial regulators of metabolism and inflammatory response [12]. Adiponectin is an aminoacid protein that exerts insulin-sensitizing, anti- inflammatory and cardioprotective effects. adiponectin was reported to reduce insulin resistance and the degree of hepatic inflammation via activation of 5-AMPactivated protein kinase and peroxisome proliferator-activated receptor-alpha pathways [13]. A growing body of evidence showed that reduced levels of adiponectin are significantly associated with obesity, type 2 diabetes, and other components of metabolic syndrome [14], [15]. Some reports demonstrated lower levels of serum adiponectin in patients with NAFLD compared to general population [16].

Previous study on Egyptians [17] examined association ADIPOQ gene polymorphism with NAFLD but did not consider the metabolic features. Moreover, other studies examined its association in other populations [18], [19]. Although a few studies have examined the association between adiponectin gene polymorphisms with risk of NAFLD [20-22], but no study regarding the association of adiponectin variants with both NAFLD and metabolic features in Egyptian population has yet been published

Therefore, we conducted the present study to evaluate the possible association between adiponectin variants of -11377 $\mathrm{C} / \mathrm{G}$ (rs266729) and susceptibility to NAFLD and abnormal metabolic features in a sample of Egyptian women.

\section{MATERIALS AND METHODS}

\subsection{Study Design and Patients selection:}

The preset study was a cross-sectional study that included 150 Egyptian women with NAFLD and 150 healthy age matched controls. All participants gave their written informed consent. Patients with documented NAFLD were recruited from Hepatology, gastroenterology and infectious diseases Department, Faculty of Medicine, girls branch from outpatient's clinic of AL-Zahraa hospital. A formal consent letter from each patient was obtained after explaining to them the whole procedure. The study was approved by the Ethics Committee of the Hospital. The individuals were interviewed by physicians. NAFLD diagnosis was based on clinical symptoms, sonographic and 
laboratory findings. Patients with viral hepatitis $\mathrm{B}$ and $\mathrm{C}$, autoimmune liver diseases, hemochromatosis, Wilson disease, and chronic drug consumption were excluded from the study.

\subsection{Anthropometric measurements and biochemical:}

The following data were collected from all eligible patients: Demographic characteristics; physical examination findings, anthropometric measurements, liver function tests, and the presence of$11377 \mathrm{C} / \mathrm{G}$ (rs266729) polymorphism. The anthropometric parameters included body weight, height, circumference of the middle upper arm, and circumferences of the waist and hip. Biceps, triceps, subcapular, suprailiac and abdominal skin fold thickness were measured as well. Serum TC and HDL-C levels were measured using a commercial kit (Roche Diagnostics, Indianapolis, IN, USA,), using Olympus AU400 automatic analyzer (Olympus Corporation, Tokyo, Japan). Serum LDL-C level was also measured using the following equation presented by [23]. Serum concentration of adiponectin was measured by Elisa kit, R\& D system.

\subsection{DNA Extraction and genotyping:}

The conventional salting out method according to [24] was used to extract the genomic DN. The DNA was extracted from peripheral blood leucocytes for all the samples collected for the purposes of this study. The genotyping of (adiponectin) gene polymorphism [ADIPOQ -11,377C/G (rs266729)] has been analyzed using the polymerase chain reaction -restriction fragment length polymorphism (PCRRFLP) method. The flanking region around the studied polymorphism was amplified using the following primers: 5'GCTCTGTGTGGACTGTGGAG-3' as forward and 5'AGAAGCAGCCTGGAGAACTG-3' as a reverse primer. The PCR products [bp] were digested using the MspI restriction endonuclease and electrophoresed on $3 \%$ agarose gel stained with Ethidium bromide.

\subsection{Statistical Analysis:}

Preparation Data analysis was carried out using SPSS (Statistical Package for the Social Science; SPSS Inc., Chicago, IL, USA) version 22 for Microsoft Windows. Quantitative data were described in terms of mean \pm standard deviation $( \pm \mathrm{SD})$, while qualitative data were expressed as frequencies (number of cases) and relative frequencies (percentages). Comparisons between quantitative variables were done using unpaired Student's t-test for parametric data or Mann-Whitney Rank Sum test for non-parametric data. Chisquare test was performed for categorical variables. A probability value ( $p$-value) less than 0.05 was considered statistically significant.

\section{Experimental Results}

The adiponectin-11377C / G (rs266729) gene polymorphisms genotype and allele frequencies are shown in Table 1. The adiponectin rs266729 polymorphism was associated with NAFLD in co-dominant, dominant, and recessive mode tested inheritance models $(\mathrm{OR}=9.24,95 \% \mathrm{CI}=$ 4.96 - 17.21, $\mathrm{P}<0.001, \mathrm{CC}$ vs. CG; and OR $=9.58,95 \% \mathrm{CI}=5.32-17.28, \mathrm{P}<0.001, \mathrm{CC}$ vs. CG - GG, respectively. Significant higher frequency of GG genotype was found in NAFLD than controls $(x 2=p<$ $0.001)$. There was a significant difference between the groups regarding to allele frequency $(x 2=p<0.0001)$. The rs266729 $\mathrm{G}$ allele showed an increase in the risk of NAFLD comparing to $\mathrm{C}$ allele $(\mathrm{OR}=6.06$, $95 \% \mathrm{CI}=3.65-10.05, \mathrm{P}<0.0001)$. Table 2 shows the anthropometric measurements and the biochemical data in both patients with NAFLD and controls. The results revealed that there was no statistical significance between the different genotyping groups regarding to the BMI. On the other hand, patients with NAFLD disease showed significant higher values regarding waist, waist to hip ratio, SBP, 
glucose, triglycerides, LDL-C and HOMAIR, and significant lower serum adiponectin in adiponectin (rs266729) gene as well as between $\mathrm{CG}$ vs. CC genotypes ( polymorphism genotypes GG vs. CC.

Table 1. The Genotypes and alleles distribution of adiponectin (rs266729) gene polymorphism in NAFLD and Controls.

\begin{tabular}{|c|c|c|c|c|}
\hline $\begin{array}{l}\text { rs266729 Poly- } \\
\text { morphism } \\
-11377 \mathrm{C} / \mathrm{G}\end{array}$ & $\begin{array}{l}\text { NAFLD } \\
\text { No. }(\%) \\
150\end{array}$ & $\begin{array}{c}\text { CONTROLS } \\
\text { No. }(\%) \\
150\end{array}$ & $\begin{array}{c}\text { OR } \\
(95 \% \mathrm{CI})\end{array}$ & $P$ value \\
\hline \multicolumn{5}{|l|}{ Co-dominant } \\
\hline$\overline{C C}$ & $65(43.33)$ & $132(88)$ & 1 & \\
\hline CG & $76(50.66)$ & $15(10)$ & $\begin{array}{c}9.24 \\
(4.96-17.21)\end{array}$ & $<0.001$ \\
\hline GG & $9(6)$ & $3(0.66)$ & $\begin{array}{c}0.60 \\
(0.09-3.63)\end{array}$ & 0.57 \\
\hline \multicolumn{5}{|l|}{ Dominant } \\
\hline $\mathrm{CC}$ & $65(43.33)$ & $132(88)$ & 1 & \\
\hline CG+GG & $85(56.66)$ & $18(12)$ & $\begin{array}{c}9.58 \\
(5.32-17.28)\end{array}$ & $<0.001$ \\
\hline \multicolumn{5}{|l|}{ Recessive } \\
\hline $\mathrm{CC}+\mathrm{CG}$ & $141(94)$ & $147(98)$ & $\begin{array}{c}3.12 \\
(0.82-0.32)\end{array}$ & 0.09 \\
\hline GG & $9(6)$ & $3(0.66)$ & & \\
\hline \multicolumn{5}{|l|}{ Alleles } \\
\hline $\bar{C}$ & $206(68.66)$ & 279(93) & 1 & \\
\hline G & 94(31.33) & 21(7) & $\begin{array}{c}6.06 \\
(3.65-10.05)\end{array}$ & $<0.0001$ \\
\hline
\end{tabular}


Table 2. Clinical characteristics in NAFLD according to the genotypes of SNP.

\begin{tabular}{|c|c|c|c|}
\hline \multirow[b]{2}{*}{ Characteristics } & \multicolumn{3}{|c|}{ Genotype } \\
\hline & GG & CG & $\mathbf{C C}$ \\
\hline BMI (kg/m2) & $31.9 \pm 3.8$ & $29.9 \pm 4.1$ & $27.9 \pm 4.7$ \\
\hline $\mathrm{WC}(\mathrm{cm}) *$ & $115.9 \pm 4.9$ & $99.9 \pm 8.5$ & $83.4 \pm 4.6$ \\
\hline Waist to hip ratio* & $0.91 \pm 0.09$ & $0.81 \pm 0.01$ & $0.71 \pm 0.02$ \\
\hline Sum of skin folds & $37.55 \pm 12.66$ & $36.50 \pm 11.65$ & $34.59 \pm 10.99$ \\
\hline Body fat $\%$ & $27.8 \pm 7.5$ & $25.8 \pm 5.9$ & $25.5 \pm 6.6$ \\
\hline SBP $(\mathrm{mmHg}) *$ & $149.3 \pm 14.1$ & $144.3 \pm 14.1$ & $109.7 \pm 10.8$ \\
\hline DBP (mmHg) & $99.0 \pm 10.6$ & $99.0 \pm 10.6$ & $69.6 \pm 11.7$ \\
\hline Glucose $(\mathrm{mg} / \mathrm{dl}) *$ & $94.3 \pm 5.4$ & $81.3 \pm 6.5$ & $78.9 \pm 4.3$ \\
\hline HOMA-IR*£ & $4.5 \pm .75$ & $2.5 \pm .95$ & $1.41 \pm .82$ \\
\hline Cholesterol (mg/dl) & $147.0 \pm 15.9$ & $144.0 \pm 18.6$ & $141.7 \pm 15.8$ \\
\hline Triglycerides $(\mathrm{mg} / \mathrm{dl}) *$ & $139.3 \pm 12.5$ & $130.3 \pm 12.5$ & $88.9 \pm 16.7$ \\
\hline HDL-C (mg/dl) & $30.7 \pm 15.9$ & $30.7 \pm 19.6$ & $49.3 \pm 18.4$ \\
\hline LDL-C (mg/dl) * & $139.5 \pm 19.8$ & $132.5 \pm 21.5$ & $105.5 \pm 26.4$ \\
\hline Adiponectin $(\mu \mathrm{g} / \mathrm{L}) *$ & $9.97 \pm 2.02$ & $12.11 \pm 2.21$ & $16.07 \pm 3.15$ \\
\hline
\end{tabular}

BMI: body mass index; HDL-C: high-density Lipoprotein-cholesterol; LDL-C: low-density lipoproteincholesterol; SBP: systolic blood pressure; DBP: diastolic blood pressure * GG vs. CC; and CG vs.CC; p < 0.01 


\section{DISCUSSION}

The present study was conducted to investigate the possible association between adiponectin gene polymorphism $11377 \mathrm{C} / \mathrm{G}$ (rs266729) in a group of Egyptian women with NAFLD. The results of genotyping showed a significant higher frequency of GG genotype in NAFLD than controls $(\mathrm{OR}=9.24, \mathrm{P}<0.001)$. There was a significant difference between the groups regarding to allele frequency. The rs266729 $\mathrm{G}$ allele showed an increase in the risk of NAFLD compared to $\mathrm{C}$ allele. Moreover, results revealed significant higher values of waist, waist to hip ratio, SBP, glucose, triglycerides, LDL-C in cases with GG genotype compared to those with the $\mathrm{CC}$.

NAFLD is a prevalent disorder with devastating consequences. Although liver biopsy is the gold standard modality for the diagnosis of NAFLD, its use is limited by sampling error and high rate of complications [25]. Over the past few decades, a number of serum biomarkers such as fatty liver index and hepatic steatosis index- were proposed as noninvasive measures for the diagnosis of NAFLD. However, these biomarkers are limited by its low diagnostic accuracy in obese patients and its inability to discriminate between various degrees of steatosis [26]. Thus, there is a critical need to investigate the clinical utility of new biomarkers for better assessment of NAFLD. Adiponectin is an amino-acid protein that is encoded by ADIPOQ gene on the chromosome locus $3 \mathrm{q} 27$, the same location of genetic alterations associated with diabetes and obesity [27], [28]. Some reports demonstrated lower levels of serum adiponectin in patients with NAFLD compared to general population, which highlights its potential role as a diagnostic biomarker for NAFLD [16]. A single nucleotide polymorphism can present at the ADIPOQ gene is named rs266729 ($11377 \mathrm{CG})$ polymorphism. Other reports have linked rs266729 polymorphism with higher susceptibility to obesity, diabetes, and insulin- resistant [29], [30]. In the present study, we found that a significant association of rs266729 (11377 G / C) polymorphism with NAFLD risk in patients carrying allele $\mathrm{G}$.

In concordance with our findings, two previous studies on Indian and Iranian populations reported a significant association between adiponectin gene polymorphism and NAFLD [31], [18]. This was similar to recent reports from Taiwan and Japan which also highlighted significant association between genotype GG and NAFLD [32], [19]. Adipokines were described as adipose tissue protein that is involved in hepatic lipid and glucose metabolism and has an important role metabolic syndrome [33].

Previous studies in Indian and Chinese NAFLD patients showed association of ADIPOQ gene with the presence and severity of disease [31], [34].

These findings were further confirmed in 2014 meta-analysis study that demonstrated significant association between ADIPOQ T45 G and G276 T genetic polymorphisms and risks of NAFLD. Previously, other study [35] demonstrated higher frequency of rs266729 G allele in NAFLD patients with history of coronary artery diseases. However, the currently published literature seems inconsistent regarding the association between adiponectin genetic polymorphism and NAFLD. For example, Wang et al. [34] reported no significant association between NAFLD and adiponectin (rs2241766 and rs1501299) polymorphisms. Later, they reported that further studies with larger samples and different ethnicities or races are needed to confirm the findings [35]. Regarding the association between rs266729 gene polymorphism and clinical parameters, we found significant difference regarding waist, waist to hip ratio, SBP, glucose, 
triglycerides, LDL-C and serum adiponectin between gene polymorphisms of $\mathrm{GG}$ versus $\mathrm{CC}$ and $\mathrm{CG}$.

\section{CONCLUSION}

In conclusion, the results of this study suggest that adiponectin (rs266729) polymorphism can be used as a helpful biomarker for NAFLD and abnormal metabolic parameters. Our findings demonstrated that $G$ allele is associated with NAFLD and with lower serum adiponectin, which may play a role in pathogenesis of NAFLD. Proper evaluation of NAFLD is likely to improve therapy effectiveness and safety management.

\section{References}

1. Pappachan, J.M., Babu, S., Krishnan, B., Ravindran, N.C., 2017. Non-alcoholic fatty liver disease: a clinical update. J. Clin. Transl. Hepatol. 5, 384.

2. Younossi, Z.M., Koenig, A.B., Abdelatif, D., Fazel, Y., Henry, L., Wymer, M., 2016. Global epidemiology of nonalcoholic fatty liver disease-meta-analytic assessment of prevalence, incidence, and outcomes. Hepatology 64, 73-84.

3. Wong, S., Ting, Y., Chan, W., 2018. Epidemiology of nonalcoholic fatty liver disease-related hepatocellular carcinoma and its implications. JGH Open 2, 235241.

4. Carr, R.M., Oranu, A., Khungar, V., 2016. Nonalcoholic fatty liver disease: pathophysiology and management. Gastroenterol. Clin. $45,639-652$.

5. Calzadilla Bertot, L., Adams, L.A., 2016. The natural course of nonalcoholic fatty liver disease. Int. J. Mol. Sci. 17, 774.

6. Armstrong, M.J., Adams, L.A., Canbay, A., Syn, W., 2014. Extrahepatic complications of nonalcoholic fatty liver disease. Hepatology 59, 1174-1197.

7. Vanni, E., Marengo, A., Mezzabotta, L., Bugianesi, E., 2015. Systemic complications of nonalcoholic fatty liver disease: when the liver is not an innocent bystander, in: Seminars in Liver Disease. Thieme Medical Publishers, pp. 236-249.

8. Severson, T.J., Besur, S., Bonkovsky, H.L., 2016. Genetic factors that affect nonalcoholic fatty liver disease: A systematic clinical review. World J. Gastroenterol. 22, 6742.

9. Petta, S., Gastaldelli, A., Rebelos, E., Bugianesi, E., Messa, P., Miele, L., Svegliati-Baroni, G., Valenti, L., Bonino, F., 2016. Pathophysiology of non-alcoholic fatty liver disease. Int. J. Mol. Sci. 17, 2082.

10. Bugianesi, E., Pagotto, U., Manini, R., Vanni, E., Gastaldelli, A., de Iasio, R., Gentilcore, E., Natale, S., Cassader, M., Rizzetto, M., 2005. Plasma adiponectin in nonalcoholic fatty liver is related to hepatic insulin resistance and hepatic fat 
content, not to liver disease severity. J. Clin. Endocrinol. Metab. 90, 3498-3504.

11. Polyzos, S.A., Aronis, K.N., Kountouras, J., Raptis, D.D., Vasiloglou, M.F., Mantzoros, C.S., 2016. Circulating leptin in nonalcoholic fatty liver disease: a systematic review and metaanalysis.

12. Pereira, S.S., Alvarez-Leite, J.I., 2014. Adipokines: biological functions and metabolically healthy obese profile. J. Recep. Lig. Channel. Res 7, 15-25.

13. Polyzos, S.A., Kountouras, J., Zavos, C., Tsiaousi, E., 2010. The role of adiponectin in the pathogenesis and treatment of nonalcoholic fatty liver disease. Diabetes, Obes. Metab. 12, 365383.

14. Arita, Y., Kihara, S., Ouchi, N., Takahashi, M., Maeda, K., Miyagawa, J., Hotta, K., Shimomura, I., Nakamura, T., Miyaoka, K., 1999. Paradoxical decrease of an adipose-specific protein, adiponectin, in obesity. Biochem. Biophys. Res. Commun. 257, 79-83.

15. Hara, K., Horikoshi, M., Yamauchi, T., Yago, H., Miyazaki, O., Ebinuma, H., Imai, Y., Nagai, R., Kadowaki, T., 2006. Measurement of the high-molecular weight form of adiponectin in plasma is useful for the prediction of insulin resistance and metabolic syndrome. Diabetes Care 29, 1357-1362.
16. Schäffler, A., Schölmerich, J., Büchler, C., 2005. Mechanisms of disease: adipocytokines and visceral adipose tissue - emerging role in nonalcoholic fatty liver disease. Nat. Clin. Pract. Gastroenterol. Hepatol. 2, 273-280.

17. Mahmoud, A.A., Moghazy, H.M., Yousef, L.M., Mohammad, A.N., 2019. Adiponectin rs2241766 and rs266729 gene polymorphisms in non-alcoholic fatty liver disease. Gene Reports 15, 100381.

18. Hashemi, M., Bojd, H.H., Nasab, E.E., Bahari, A., Hashemzehi, N.A., Shafieipour, S., Narouie, B., Taheri, M., Ghavami, S., 2013. Association of adiponectin rs1501299 and rs266729 gene polymorphisms with nonalcoholic fatty liver disease. Hepat. Mon. 13.

19. Tokushige, K., Hashimoto, E., Noto, H., Yatsuji, S., Taniai, M., Torii, N., Shiratori, K., 2009. Influence of adiponectin gene polymorphisms in Japanese patients with non-alcoholic fatty liver disease. J. Gastroenterol. 44, 976982.

20. Musso, G., Gambino, R., De Michieli, F., Durazzo, M., Pagano, G., Cassader, M., 2008. Adiponectin gene polymorphisms modulate acute adiponectin response to dietary fat: Possible pathogenetic role in NASH. Hepatology 47, 1167-1177.

21. Wong, V.W., Wong, G.L., Tsang, S.W., Hui, A.Y., Chan, A.W., Choi, P.C., So, W., Tse, A.M., Chan, F.K., Sung, J.J., 2008. Genetic 
polymorphisms of adiponectin and tumor necrosis factor-alpha and nonalcoholic fatty liver disease in Chinese people. J. Gastroenterol. Hepatol. 23, 914-921.

22. Zhou, Y., Li, Y., Nie, Y., Yang, H., Zhan, Q., Huang, J., Shi, S., Lai, X., Huang, H., 2010. Influence of polygenetic polymorphisms on the susceptibility to non-alcoholic fatty liver disease of Chinese people. J. Gastroenterol. Hepatol. 25, 772777.

23. Friedewald, W.T., Levy, R.I., Fredrickson, D.S., 1972. Estimation of the concentration of low-density lipoprotein cholesterol in plasma, without use of the preparative ultracentrifuge. Clin. Chem. 18, 499-502.

24. Miller, S.A., Dykes, D.D., Polesky, H., 1988. A simple salting out procedure for extracting DNA from human nucleated cells. Nucleic Acids Res. 16, 1215.

25. Merat, S., Sotoudehmanesh, R., Nouraie, M., Peikan-Heirati, M., Sepanlou, S.G., Malekzadeh, R., Sotoudeh, M., 2012. Sampling error in histopathology findings of nonalcoholic fatty liver disease: a postmortem liver histology study. Arch Iran Med 15, 418-421.

26. Zhou, J.-H., Cai, J.-J., She, Z.-G., Li, H.-L., 2019. Noninvasive evaluation of nonalcoholic fatty liver disease: Current evidence and practice. World J. Gastroenterol. 25, 1307.
27. Mori, Y., Otabe, S., Dina, C., Yasuda, K., Populaire, C., Lecoeur, C., Vatin, V., Durand, E., Hara, K., Okada, T., 2002. Genome-wide search for type 2 diabetes in Japanese affected sib-pairs confirms susceptibility genes on $3 q$, $15 q$, and $20 \mathrm{q}$ and identifies two new candidate Loci on $7 \mathrm{p}$ and $11 \mathrm{p}$. Diabetes 51, 1247-1255.

28. Saito, K., Tobe, T., Minoshima, S., Asakawa, S., Sumiya, J., Yoda, M., Nakano, Y., Shimizu, N., Tomita, M., 1999. Organization of the gene for gelatin-binding protein (GBP28). Gene 229, 67-73.

29. Mohammadzadeh, G., Zarghami, N., 2009. Associations between single-nucleotide polymorphisms of the adiponectin gene, serum adiponectin levels and increased risk of type 2 diabetes mellitus in Iranian obese individuals. Scand. J. Clin. Lab. Invest. 69, 764-771.

30. Motawi, T., Salman, T., Shaker, O., Abdelhamid, A., 2015. Association of polymorphism in adiponectin (+ $45 \mathrm{~T} / \mathrm{G})$ and leptin (-2548 G/A) genes with type 2 diabetes mellitus in male Egyptians. Arch. Med. Sci. AMS 11, 937.

31. Gupta, A.C., Misra, R., Sakhuja, P., Singh, Y., Basir, S.F., Sarin, S.K., 2012. Association of adiponectin gene functional polymorphisms ($11377 \mathrm{C} / \mathrm{G}$ and $+45 \mathrm{~T} / \mathrm{G})$ with nonalcoholic fatty liver disease. Gene 496, 63-67.

32. Hsieh, C.-J., Wang, P.W., Hu, T.H., 2015. Association of adiponectin gene polymorphism with 
nonalcoholic fatty liver disease in Taiwanese patients with type 2 diabetes. PLoS One 10.

33. Ouchi, N., Parker, J.L., Lugus, J.J., Walsh, K., 2011. Adipokines in inflammation and metabolic disease. Nat. Rev. Immunol. 11, 85-97.

34. Wang, Z.L., Xia, B., Shrestha, U., Jiang, L., Ma, C.W., Chen, Q., Chen, H., Hu, Z.G., 2008. Correlation between adiponectin polymorphisms and non-alcoholic fatty liver disease with or without metabolic syndrome in Chinese population. J. Endocrinol. Invest. 31, 1086-1091.

35. Wang, Bai-Fang, Wang, Y., Ao, R., Tong, J., Wang, Bing-Yuan, 2016. AdipoQ T45 G and G276 T Polymorphisms and Susceptibility to Nonalcoholic Fatty Liver Disease Among Asian Populations: A Meta-Analysis and MetaRegression. J. Clin. Lab. Anal. 30, 47-57. 